\title{
Method and mechanism of dispersing agent free dispersion of short carbon fibers in silicon carbide powder
}

\author{
Thakur Sudesh Kumar Raunija*, Mariamma Mathew and Sharad Chandra Sharma \\ Materials and Mechanical Entity, Vikram Sarabhai Space Centre, Indian Space Research Organisation, Thiruvananthapuram-695022, \\ Kerala, India
}

\author{
Article Info \\ Received 8 March 2014 \\ Accepted 27 June 2014 \\ *Corresponding Author \\ E-mail: thakurskr@gmail.com
}

\section{Open Access}

DOI: http://dx.doi.org/

10.5714/CL.2014.15.3.180

This is an Open Access article distributed under the terms of the Creative Commons Attribution Non-Commercial License (http://creativecommons.org/licenses/ by-nc/3.0/) which permits unrestricted non-commercial use, distribution, and reproduction in any medium, provided the original work is properly cited.

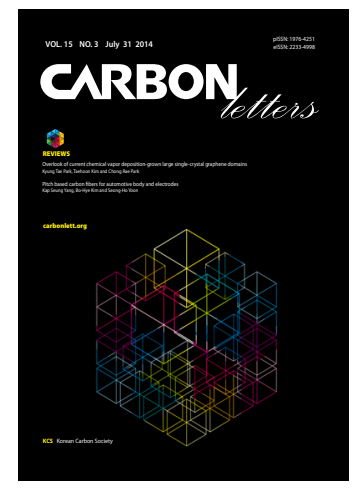

http://carbonlett.org

pISSN: 1976-4251

elSSN: 2233-4998

Copyright $\odot$ Korean Carbon Society

\begin{abstract}
This study highlights a novel method and mechanism for the rapid and effective milling of carbon fibers (CFs) in silicon carbide ( $\mathrm{SiC}$ ) powder, and also the dispersion of CFs in $\mathrm{SiC}$ powder. The composite powders were prepared by chopping and exfoliation of CFs, and ball milling of CFs and $\mathrm{SiC}$ powder in isopropyl alcohol. A wide range of CFs loading, from 10 to $50 \mathrm{vol} \%$, was studied. The milling of $\mathrm{CFs}$ and $\mathrm{SiC}$ powder was checked by measuring the average particle size of the composite powders. The dispersivity of CFs in $\mathrm{SiC}$ powder was checked through scanning electron microscope. The results show that the usage of exfoliated $\mathrm{CF}$ tows resulted in a rapid and effective milling of CFs and $\mathrm{SiC}$ powder. The results further show an excellent dispersion of CFs in $\mathrm{SiC}$ powder for all CFs loading without any dispersing agent.
\end{abstract}

Key words: short carbon fibers, silicon carbide, chopping, grinding, exfoliation, milling, dispersion and average particle size

\section{Introduction}

The space programmes of several countries have established themselves as reliable and excellent service providers worldwide in the fields of remote sensing, communications, weather forecasting, satellite education, telemedicine, etc., by launching commercial satellites. The Indian space programme is among those who have also established themselves as service providers using polar satellite launch vehicles and geosynchronous satellite launch vehicles. Presently, the cost of space exploration by the Indian Space Research Organization (ISRO) is relatively low as compared with other space agencies. However, ISRO is endeavoring to further lower the cost of space exploration, so that space services can be delivered to every last person on the planet.

Various systems play key roles in controlling the cost of space exploration [1]. Materials are pivotal to the costs of almost all systems. Hence, the goal of reducing costs can't be achieved without developing advanced materials. The development of a new class of lighter and cheaper materials whose performance can match that of existing materials is the need of the hour. Composites are the most promising materials in this category [2]. They are lighter, cheaper and can be tailored to meet specified requirements. Various types of composite are already being used for space applications [3-7]. One of these is the class of carbon/silicon carbide composites ( $\mathrm{C} / \mathrm{SiC}$ composites).

$\mathrm{C} / \mathrm{SiC}$ composites possess an excellent set of properties including strength, stiffness, oxidation resistance, creep resistance and chemical stability. Additionally, they have low density and low wear [8]. Since they retain most of their properties at elevated temperature, they can be used for high temperature applications. Further, their excellent set of thermo-structural properties coupled with low density make them the best candidate for aerospace applications such as wing leading edges, etc. [9]. Additionally, they have important applications in the field of high temperature sensors, optoelectronics and brake discs $[6,10]$. 
A good amount of work has been done on various aspects of $\mathrm{C} / \mathrm{SiC}$ composites. However, much of the focus to date has been on fabrication routes and techniques. Among these routes and techniques, continuous carbon fiber (CF) reinforced $\mathrm{SiC}$ matrix composites have occupied the centre stage [11-14]. In the last couple of years, short fiber reinforced composites have attracted the attention of material scientists and designers due to several advantages. Mainly, the use of short fibers as reinforcement is a way to reduce the cost of the composites. The short fiber reinforced composites are increasingly used in a wide range of applications because of their easy adaptability to conventional manufacturing techniques and ease of fabrication [15-19].

In a short $\mathrm{CF}$ reinforced $\mathrm{SiC}$ matrix composite system, the properties of the composites can also be tailored to a large extent, as required. This tailorability and the end properties of short $\mathrm{CF}$ reinforced $\mathrm{C} / \mathrm{SiC}$ composites depend upon various parameters. These parameters include the distribution of the CFs in the $\mathrm{SiC}$ matrix and the average particle size (APS) of the charge (CFs and powdered $\mathrm{SiC}$ ). The agglomeration-free distribution of $\mathrm{CFs}$ in the $\mathrm{SiC}$ matrix also plays a key role in interphase bonding, crack propagation, mode of failure, etc. The particle size of the starting materials has long been recognized as a key factor in the end properties of a material. Further, the packing density increases with decreasing particle size. Achieving agglomerationfree distribution of CFs in SiC powder and controlling APS are both very complex due to differences in the nature and density of CFs and $\mathrm{SiC}$.

Although a good amount of work has been accomplished with $\mathrm{C} / \mathrm{SiC}$ composites by varying processing conditions, sintering aids and the ratio of reinforcement to matrix [15-19], not much attention has been given to the dispersion and distribution of short fibers in ceramic powders. Some work has been reported on the dispersion of $\mathrm{CFs}$ in $\mathrm{SiC}$ powder, but such attempts have been made using dispersing agents. According to reports by various researchers, the usage of such agents can disperse the $\mathrm{CFs}$ in $\mathrm{SiC}$ to some extent, but the lengthy cycle of processing yielded damage to the CFs' surface [20]. Hence, the emergence of newer methods and techniques for the dispersion of CFs in $\mathrm{SiC}$ powder will be a milestone in advancing the adoption of short $\mathrm{CF}$ reinforced $\mathrm{SiC}$ composites.

Along that line, we have explored a methodology involving the exfoliation of CFs prior to ball milling. To the best of the authors' knowledge, no work has previously been reported on the agglomeration-free dispersion and distribution of CFs in $\mathrm{SiC}$ powder using the concept of exfoliation of CFs prior to ball milling. Additionally, the mechanism behind fiber size reduction and splitting has not yet been reported. In our study, efforts were made to establish an effective and rapid method for the milling and dispersion of CFs in $\mathrm{SiC}$ powder by employing exfoliated $\mathrm{CFs}$ along with $\mathrm{SiC}$ powder in wet milling. This paper reports the rapid and effective fiber dispersing method and its mechanisms.

\section{Materials and Methods}

Polyacrylonitrile (PAN) based CFs (T-300, 3K; Torayca Co., Japan $)$ and $\mathrm{SiC}$ powder $(7.361 \mu \mathrm{m}$ APS, $\alpha$-grade $)$ were taken for the milling experiments. Isopropyl alcohol (IPA) was employed
Table 1. Properties of carbon fibers

\begin{tabular}{cc} 
Properties & Value \\
\hline Density $\left(\mathrm{g} / \mathrm{cm}^{3}\right)$ & 1.77 \\
Tensile strength $(\mathrm{GPa})$ & 5.3 \\
Tensile modulus $(\mathrm{GPa})$ & 276 \\
Elongation $(\%)$ & 1.81 \\
Coefficient of thermal expansion $\left(10^{-6} /{ }^{\circ} \mathrm{C}\right)$ & - \\
\hline
\end{tabular}

Table 2. Properties of isopropyl alcohol

\begin{tabular}{cc} 
Properties & Value \\
\hline Boiling range $\left({ }^{\circ} \mathrm{C}\right)$ & $81-83$ \\
Assay $(\%)$ & 99.0 \\
Wt per mL at $20^{\circ} \mathrm{C}(\mathrm{g})$ & $0.783-0.786$ \\
Non-volatile matter $(\%)$ & 0.01 \\
Grade & Laboratory reagent \\
\hline
\end{tabular}

Table 3. Properties of SiC powder

\begin{tabular}{cc} 
Properties & Value \\
\hline Diffusion range $\left({ }^{\circ} \mathrm{C}\right)$ & $2000-2500$ \\
Particle size $(\mu \mathrm{m})$ & 0.7 \\
Density $\left(\mathrm{g} / \mathrm{cm}^{3}\right)$ & 3.2 \\
Grade & Alpha \\
\hline
\end{tabular}

SiC: silicon carbide.

Table 4. Sample designation

\begin{tabular}{cc} 
Sample No. & Parameters \\
\cline { 2 - 2 } & CF:SiC ratio \\
\hline TSM-00 & $00: 100$ \\
TSM-01 & $10: 90$ \\
TSM-02 & $20: 80$ \\
TSM-03 & $30: 70$ \\
TSM-05 & $50: 50$ \\
\hline
\end{tabular}

CF: carbon fiber, SiC: silicon carbide.

as a slurry media for the wet milling of $\mathrm{CFs}$ and $\mathrm{SiC}$ powder. The properties of the raw materials are summarized in Tables 1-3. The designation of the samples processed under different processing conditions is given in Table 4 .

The continuous CFs from a fiber spool were chopped into discrete lengths using in-house designed and developed fiber milling equipment (Fig. 1) and a method of un-interrupted fiber milling. Discrete CFs of $3 \mathrm{~mm}$ length were obtained using this 


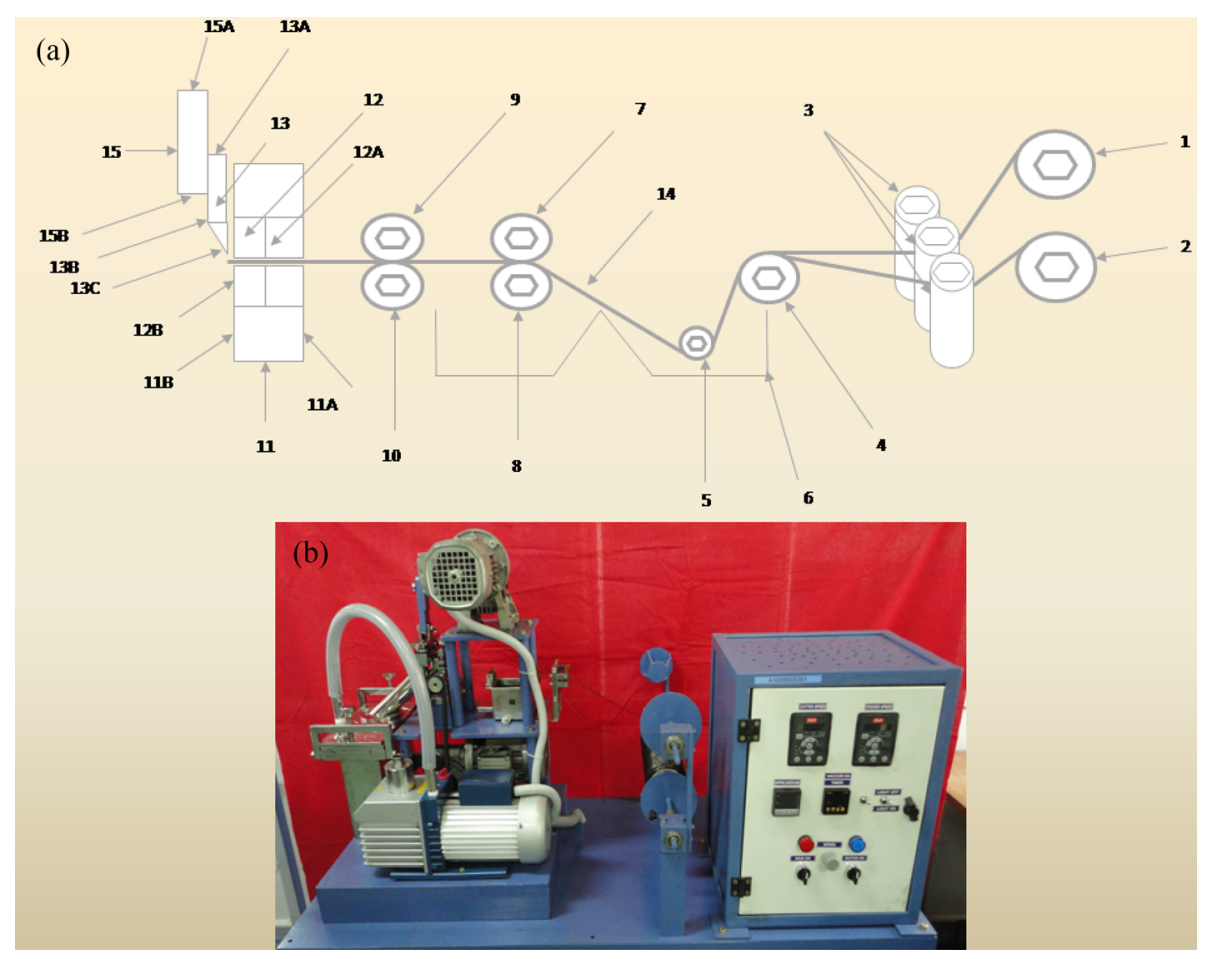

Fig. 1. Method and machine for the chopping of carbon fibers, (a) schematic representation of the chopping process, (b) digital image of fiber milling equipment. 1 and 2: carbon fiber spools, 3: vertical straightening rollers, 4: horizontal guiding roller, 5: water immersing roller, 6: water tank, 7 and 8: water squeezing rollers, 9 and 10: moving rollers, 11: stationary blade holder, 12: stationary blade, 13: moving blade, 14: carbon fiber tows, 15: moving blade holder.

fiber milling equipment.

The chopped CFs of $3 \mathrm{~mm}$ length obtained from the fiber milling equipment were ground using a domestic mixer-grinder (Sumit). Grinding is basically a size reduction operation. It employs an attrition and impact mechanism to reduce the size of solids/powders. Attrition means reduction in size by rubbing against the solid jar's wall, blades, etc. Impact means reduction in size by direct hitting of the solid blades on the surface of the material which is to be reduced. The latter mechanism was found to be prominent in the grinding of CFs for exfoliation. The grinding was done for a total of $4 \mathrm{~min}$ in 16 cycles of $15 \mathrm{~s}$ each.

A ball mill (Fritsch, Pulversette P5 model) was employed for the milling study. Bowls (SS with an inner coating of silicon-nitride) of size $\varnothing 74.5 \times 70 \mathrm{~mm}$, and balls (small balls of $\varnothing 10 \mathrm{~mm}$ and big balls of $\varnothing 20 \mathrm{~mm}$ ) were used for this operation. The balls were also silicon-nitride. Milling is basically a size reduction operation like grinding. Unlike grinding, it is used to produce a very fine particle size. The ground exfoliated CF tows were dispersed in IPA ( $20 \mathrm{~mL}$ per $1 \mathrm{~cm}^{3}$ of charge) with $\mathrm{SiC}$ powder. The powder mixtures were milled for $4 \mathrm{~h}$ in 8 cycles ( $30 \mathrm{~min}$ operation per cycle) with a soaking time of $5 \mathrm{~min}$ after each cycle. The main objective of giving residence time in between cycles was to minimize heat generated during milling and to protect the material from any damage due to overheating.

An electric air oven (Thermosystem) capable of maximum heating up to $300^{\circ} \mathrm{C}$ was used for the air-drying operation. The slurries of the samples were dried for $8 \mathrm{~h}$ at $90^{\circ} \mathrm{C} @ 5^{\circ} \mathrm{C} / \mathrm{min}$. The drying operation was basically carried out to evaporate IPA from the slurry of CFs and SiC.

After air drying, the powder mixtures were found to have certain agglomerates. To break down these agglomerates to a finer scale, the powder mixtures were crushed using a domestic mixer-grinder in 4 cycles. In each cycle, crushing was carried out for $15 \mathrm{~s}$ in pulse form to avoid wear on the blades due to the $\mathrm{SiC}$ powder.

After the crushing operation, the powders of all the samples were characterized to determine the dispersion of the CFs and their distribution in the $\mathrm{SiC}$ powder. The microstructure analysis of samples was carried out using a Carl Zeiss SMT EVO 50 model scanning electron microscope (SEM). SEM images were taken under variable pressure using $80 \mathrm{P}$ air pressure. Filament of LaB6 was employed for taking the images.

The APS (volume weighted mean) of all the samples after the crushing operation was characterized using size analyser (Mastersizer 2000 Ver. 5.22) from Malvern Instrument Ltd., UK. The APS was checked after completing all the operations of size reduction, exfoliation, dispersion, drying, and flocculation removal.

\section{Results and Discussion}

As milling and dispersion play an important role in the end properties of $\mathrm{C} / \mathrm{SiC}$ composites made by the sintering route, a study comprised of chopping, grinding, milling, air drying and crushing was carried out to prepare and disperse the CFs in 


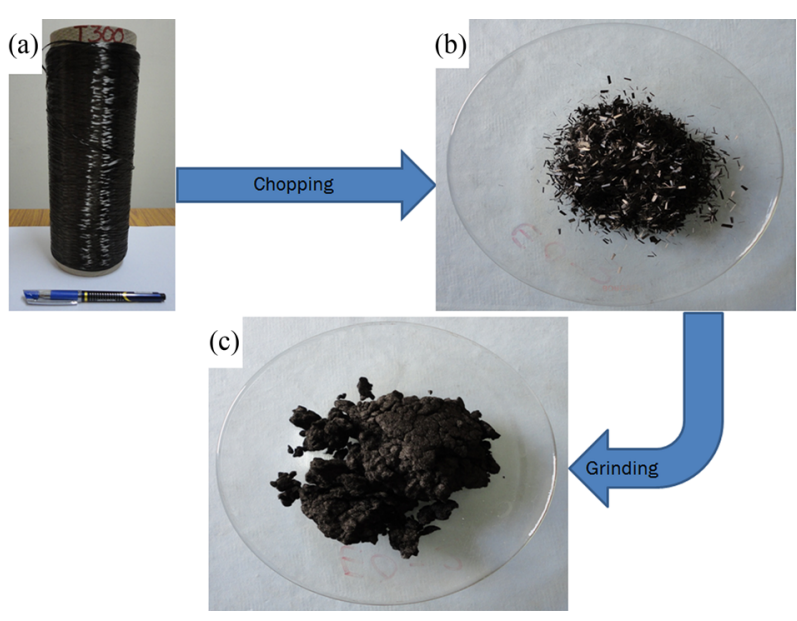

Fig. 2. Digital images of, (a) continuous carbon fiber spool, (b) chopped carbon fiber tows, c) exfoliated ground carbon fiber tows.
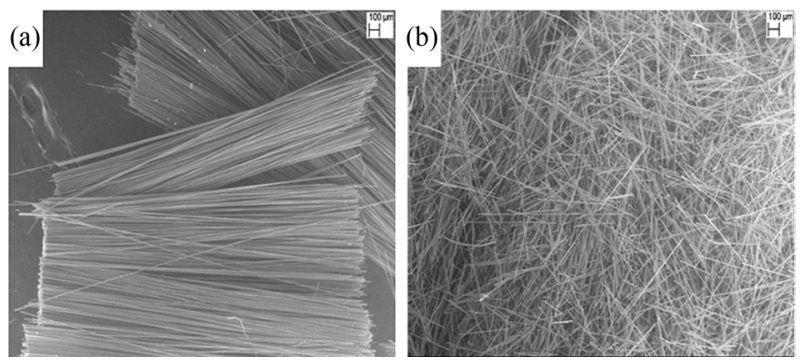

Fig. 3. Scanning electron microscope micrographs of, (a) un-exfoliated carbon fiber tows, (b) exfoliated carbon fibers.

SiC powder. Continuous CFs from a fiber spool (Fig. 2a) were chopped using in-house developed equipment and technology into discrete $3 \mathrm{~mm}$ lengths (Fig. 2b). Using fiber milling equipment the CFs were chopped into a higher aspect ratio; this was intended to speed up the process of charge preparation, as the chopping of CFs into short lengths typically takes enormous time. The chopped CFs were then further ground using a mixergrinder. During the grinding operation, the size of the CFs was reduced from $3 \mathrm{~mm}$ to approximately $1 \mathrm{~mm}$. The size of the CFs was certified by visual inspection and manual measurement. Further grinding resulted in quite good exfoliation of CF tows. A digital image of exfoliated ground $\mathrm{CF}$ tows is depicted in Fig. 2c.

A microscopic analysis of the effectiveness of CFs exfoliation using the mixer-grinder was done by taking SEM micrographs of un-exfoliated tows and exfoliated tows. The SEM images of the chopped CF tows and exfoliated CFs are shown in Fig. 3. From Figs. 3a and b, it can be clearly seen that the bunch of filaments bound in a single discrete tow has been exfoliated. The exfoliated CF tows (Fig. 4b) and SiC powder (Fig. 4a) were further ball milled using IPA as slurry media. The powder mixture obtained after ball milling, drying and crushing of CFs and $\mathrm{SiC}$ powder is depicted in Fig. 4c. It can be seen from Fig. 4c that the CFs are dispersed uniformly in the $\mathrm{SiC}$ powder. The microscopic analysis of the dispersion of $\mathrm{CFs}$ in $\mathrm{SiC}$ powder is addressed in later paragraphs.

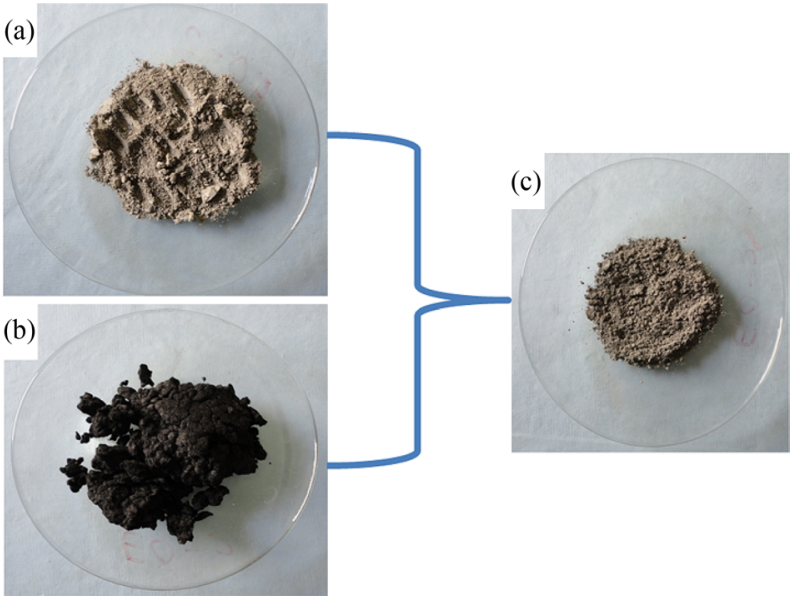

Fig. 4. Digital images of, (a) silicon carbide powder, (b) exfoliated carbon fibers, (c) ball milled mixture of carbon fibers and silicon carbide powder.
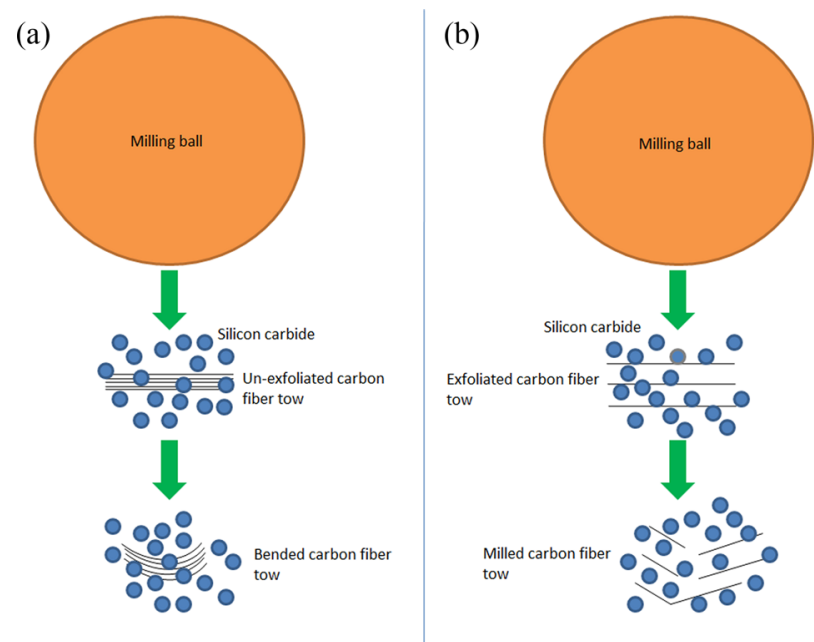

Fig. 5. Conceptual models of interaction of milling ball with carbon fibers and silicon carbide powder for, (a) un-exfoliated carbon fiber tow, (b) exfoliated carbon fiber tow.

The main motive for exfoliating the chopped fiber tows prior to ball milling was to further reduce the length of the CFs at a faster rate than conventional methods, and also to aid in the uniform dispersion of $\mathrm{CFs}$ in $\mathrm{SiC}$ powder. Because the exfoliated $\mathrm{CF}$ tows allowed $\mathrm{SiC}$ powder to go in between the individual filaments as soon as the ball milling operation was started, the milling was quite easy and rapid. The probable mechanism behind the effect of exfoliation on the milling and dispersion of $\mathrm{CFs}$ in $\mathrm{SiC}$ powder was conceptualized. The conceptual arrangement of this phenomenon is depicted in Fig. 5.

From Figs. 5a and b, it can be seen that the fine particles of $\mathrm{SiC}$ are unable to go in between filaments of an un-exfoliated tow because of the very tiny gap available between the filaments. Hence, the impact delivered by the milling ball can't break the filaments. This may result in a bended tow as shown in Fig. 5a. On the other hand, the fine particles of $\mathrm{SiC}$ can enter 

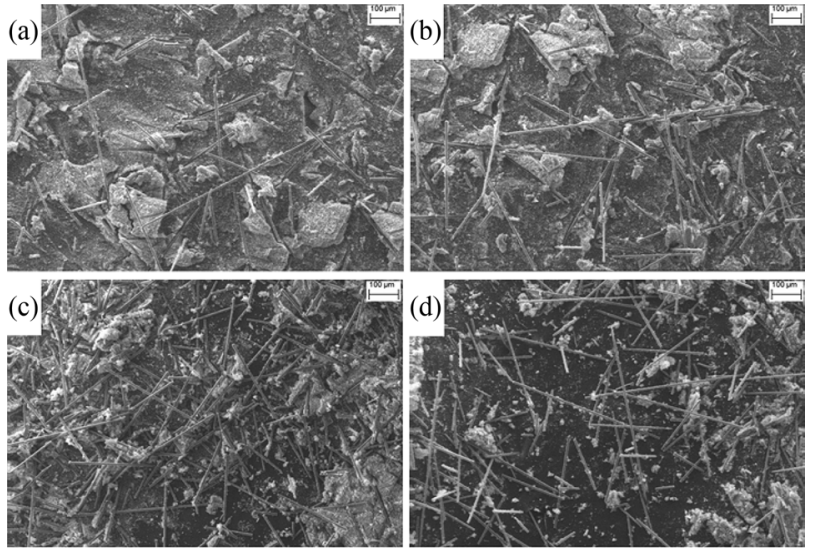

Fig. 6. Scanning electron microscope micrographs of ball milled samples of carbon fibers and silicon carbide, (a) TSM-01, (b) TSM-02, (c) TSM03, (d) TSM-05.

in between filaments of an exfoliated tow as depicted in Fig. $5 \mathrm{~b}$. As the particles of $\mathrm{SiC}$ are harder than the carbon filaments, milling of the carbon filaments will take place when they are impacted by the milling ball (Fig. 5b). Additionally, the exfoliation of the CF tows aided in the fine dispersion (Fig. 6) of CFs in the $\mathrm{SiC}$ powder. Further, the usage of the grinding operation for the exfoliation and shortening of CF tows resulted in an enormous reduction in milling and dispersion time. Excellent dispersion (Fig. 6) and milling of CFs in $\mathrm{SiC}$ powder was achieved in $4 \mathrm{~h}$ of ball milling, whereas Hao et al. [20] study of the dispersion of CFs in $\mathrm{SiC}$ powder using dispersing agents involved a very long duration (48-72 h). Further, even with dispersing agents and after prolonged milling, they could disperse only $30 \mathrm{vol} \%$ of CFs in $\mathrm{SiC}$ powder, whereas we could disperse up to $50 \mathrm{vol} \%$ of $\mathrm{CFs}$ in $\mathrm{SiC}$ powder.

Additionally, as is evident from Fig. 6, dispersion of the CFs in $\mathrm{SiC}$ powder was achieved without damaging the surface of CFs, whereas damage to CFs' surface was reported by Hao et al. [20]. The main cause behind that damage was the prolonged milling they carried out [20] whereas we could disperse CFs in a short span of time by incorporating the exfoliation step, which aided in achieving excellent dispersion without damaging the CFs' surface.

Further, from Fig. 6, it can be seen that not even one single spot is visible where two or more CF filaments are stacked together axially. This shows that there was excellent dispersion of $\mathrm{CFs}$ in $\mathrm{SiC}$ powder for all vol $\%$ of $\mathrm{CFs}$.

Though distribution of the CFs is also quite good, the results are not similar to dispersion. It can also be seen from Fig. 6, that the distribution is extremely uniform for 10 and $20 \mathrm{vol} \%$ of CFs, whereas it is moderately good for 30 and $50 \mathrm{vol} \%$ of CFs. This indicates the dependency of distribution on the loading of CFs. The loading of $20 \mathrm{vol} \%$ for CFs is very critical as far as distribution is concerned for this particular set of parameters. This might have happened due to the tendency of CFs to agglomerate at higher vol\%, which would have led to the formation of some pocket zones, as depicted in Figs. 6c and d, of slightly higher concentration of CFs.

The APS of CFs and SiC ball milled powders was measured.
Table 5. Average particle size of powder samples

\begin{tabular}{cc} 
Sample No. & APS $(\mu \mathrm{m})$ \\
\hline TSM-00 & 7.361 \\
TSM-01 & 9.457 \\
TSM-02 & 9.851 \\
TSM-03 & 10.189 \\
TSM-05 & 11.679 \\
\hline
\end{tabular}

APS: average particle size.

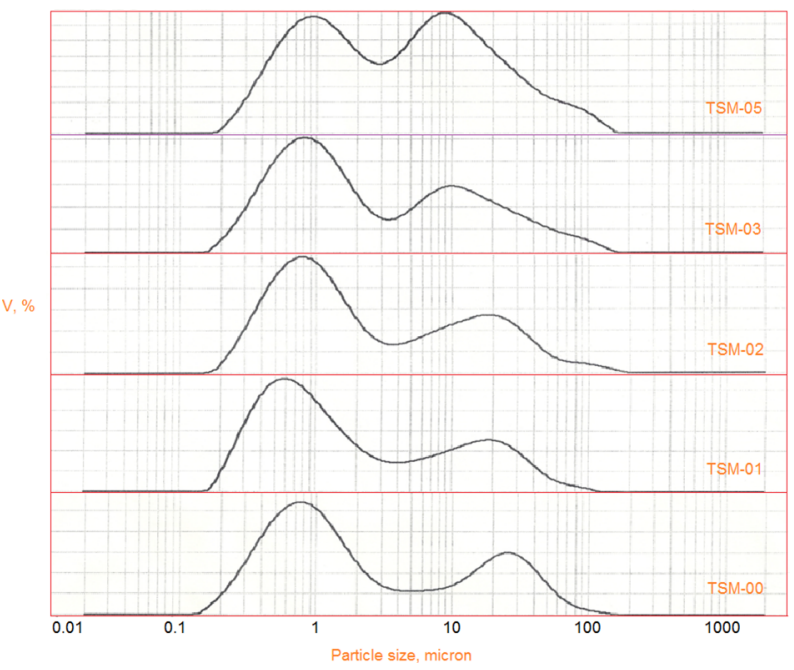

Fig. 7. Particle size distribution with the loading of carbon fibers.

Ground exfoliated CFs of approximately $1 \mathrm{~mm}$ got reduced to APS in the range of 9.5 to $11.7 \mu \mathrm{m}$ depending upon the vol\% of CFs in the SiC powder. The APS of all the samples is summarized in Table 5. The particle size distribution of CFs in $\mathrm{SiC}$ powder, for all the samples, is clubbed and presented in Fig. 7. As can be seen from Table 5, the APS of TSM-01, TSM-02, and TSM-03 increases linearly with CFs loading, whereas for TSM05, the increase in APS is very sharp. However, the APS has increased for all CFs loadings.

A similar trend is shown by the particle size distribution of the composite mixtures. As is evident from Fig. 7, the sharpness of the second peak, which reflects the presence and milling efficiency of CFs, diminishes as the loading of CFs is increased from 0 to $10 \mathrm{vol} \%$, and this trend continues till the loading reaches 30 vol $\%$. This peak becomes extremely broad and tall as the loading increases from 30 to $50 \mathrm{vol} \%$. This might have happened either due to the difference between the sizes of the CFs and $\mathrm{SiC}$ powder, or the poor milling of $\mathrm{CFs}$ in $\mathrm{SiC}$ powder. Regarding the first cause, as we increased the vol $\%$ of particles with higher APS in a mixture of lower ones, the APS of the resultant mixture went up. It can be seen from Table 5 that the APS has increased enormously, from 7.361 to $9.457 \mu \mathrm{m}$, or $28.47 \%$, as the loading of CFs increased from 0 to $10 \mathrm{vol} \%$. This resulted purely from the addition of particles of higher APS into those of lower APS. 

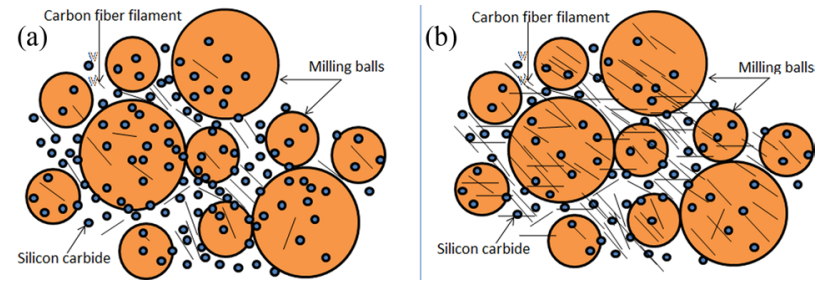

Fig. 8. Conceptual model of interaction of milling balls with carbon fibers and silicon carbide, (a) low carbon fiber loading, (b) high carbon fiber loading.

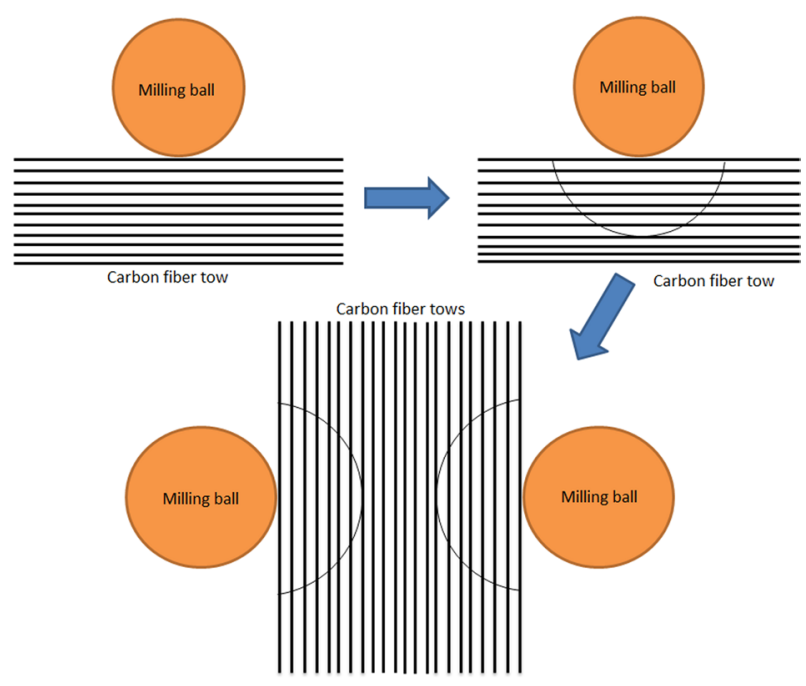

Fig. 9. Conceptual model of interaction of milling ball with agglomerated carbon fiber tow having a greater number of exfoliated carbon filaments.

Unlike that situation, however, the increase in APS is marginal, i.e. $4.17 \%$, when the CFs loading is increased from 10 to $20 \mathrm{vol} \%$. Similarly, the increase in APS is very low, i.e. $3.43 \%$, when CFs loading is increased from 20 to $30 \mathrm{vol} \%$. This implies that the increase in APS is mainly dominated by the addition of higher APS particles into that of lower APS, which increases the APS of the resultant mixture.

However, this trend is different in the case of sample TSM-05. The increase in APS is appreciable, i.e. $14.62 \%$, as CFs loading is increased from 30 to $50 \mathrm{vol} \%$. This implies that in addition to increases resulting from the addition of higher APS particles to lower APS, which increases the APS of the resultant mixture, the APS is also controlled by something else. This other phenomenon might be poor milling, i.e. the shortening of CFs' length, resulting in the higher APS of the resultant mixture at higher loading of $\mathrm{CFs}$ in $\mathrm{SiC}$ powder. The poor milling of $\mathrm{CFs}$ in composite mixtures could have occurred as a result of increased loading of CFs, which would have resulted in a reduction in the number of hits per unit fiber filament from the milling balls. In addition, it is well known that during ball milling, size reduction is mainly caused by attrition and compression, and both of these size reduction mechanisms depend upon the number of ball hits received by the solid particles to be milled. In the same period of time, the number of

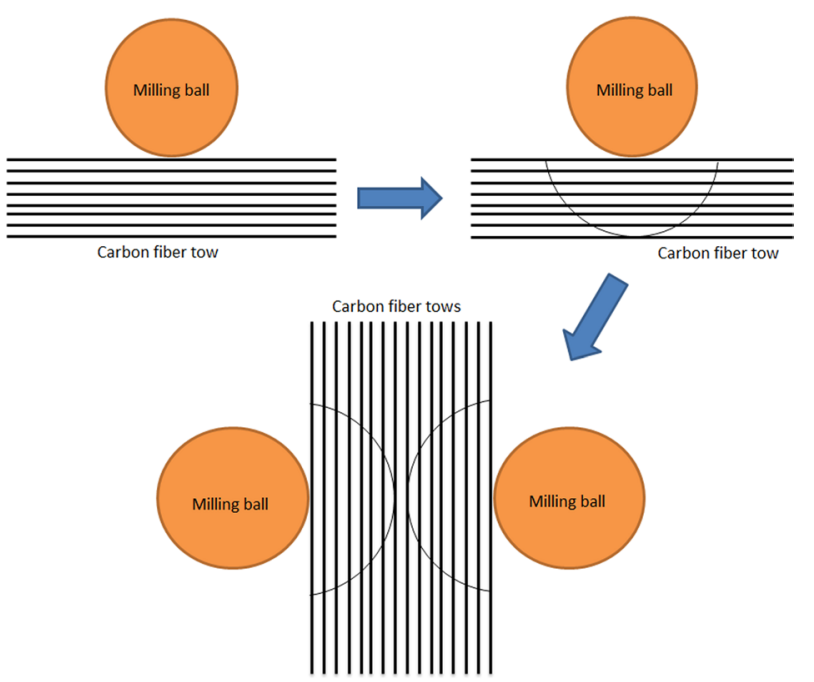

Fig. 10. Conceptual model of interaction of milling ball with agglomerated carbon fiber tow having a smaller number of exfoliated carbon filaments.

hits per filament will decrease when there are increasing numbers of CF filaments in the powder, resulting in less effective milling.

This can be easily understood with the help of Figs. 8-10. Figs. 8a and $\mathrm{b}$ represent the stationary arrangement of short $\mathrm{CF}$ filaments, $\mathrm{SiC}$ powder and milling balls for low and high vol $\%$ of CFs, respectively. As we can see from Figs. 8a and b, at lower vol $\%$ of CFs, each filament can receive a higher number of direct hits from the milling balls, whereas at higher vol\% of CFs each filament will receive fewer direct hits from the milling balls, resulting in poorer milling of the $\mathrm{CF}$ filaments at higher vol\% of $\mathrm{CFs}$ in the $\mathrm{SiC}$ powder.

Also, during the milling operation some of the exfoliated CFs would have come close to each other. This closeness would have been more frequent for the samples with higher CFs loading than for those with lower CFs loading. Due to the increased closeness of the CFs, the interior filaments as depicted in Fig. 9 would have been shielded, and not have experienced the direct impact of the milling ball, whereas in the case of less CFs closeness, the interior filaments as depicted in Fig. 10 would have experienced the hit by the milling ball. As a result of the occurrence of this phenomenon, the milling of $\mathrm{CFs}$ in $\mathrm{SiC}$ powder would have been poorer, which resulted in higher APS for TSM- 05 with 50 vol $\%$ CFs loading.

\section{Conclusions}

A novel methodology for the dispersion of CFs in $\mathrm{SiC}$ powder without any dispersing agent was established and demonstrated successfully. The probable mechanism behind the rapid and effective dispersion of CFs, resulting from the inclusion of an exfoliation step in the method, was conceptualized and explained. The method's rapid dispersion of CFs in $\mathrm{SiC}$ powder was found to be very promising for obtaining damage free $\mathrm{CF}$ reinforced $\mathrm{SiC}$ composite mixtures. Further results on the influence of various ball milling and exfoliation parameters on the dispersion of $\mathrm{CFs}$ in $\mathrm{SiC}$ powder will be reported later. 


\section{Acknowledgments}

The authors are thankful to Shri V. K. Vineeth and Shri Omendra Mishra, CCCS/AMCD for their commendable assistance in carrying out the experiments. The authors are also grateful to Shri Sushant K. Manwatkar, Ms. M. Swamthi Kiranmayee and Shri A. K. Jha, MCD/MME for their support rendered in taking SEM micrographs of the samples. The authors express their sincere thanks to Ms. Suchithra and Dr. Neeraj Naithani for their support in characterizing APS. The authors are thankful to Shri S. Babu, PPEC/MMG for his valuable suggestions, technical discussions and moral support rendered in carrying out this study. The authors express their sincere thanks to Dr. Koshy M. George, Deputy Director, Vikram Sarabhai Space Centre for the encouragement given to $\mathrm{C} / \mathrm{SiC}$ composites activity.

\section{References}

[1] Ashcroft D. Space Exploration: All That Matters, Hodder \& Stoughton, UK (2013).

[2] Quilter A. Composites in aerospace applications. IHS White Paper, 444, 1 (2001)

[3] Soutis C. Fibre reinforced composites in aircraft construction. Prog Aerosp Sci, 41, 143 (2005). http://dx.doi.org/10.1016/j.paerosci.2005.02.004.

[4] Raunija TSK, Manwatkar SK, Sharma SC, Verma A. Morphological optimization of process parameters of randomly oriented carbon/carbon composite. Carbon Lett, 15, 25 (2014). http://dx.doi. org/10.5714/CL.2014.15.1.025.

[5] Raunija TSK, Babu S, Wesley C. A process of producing carbon/ carbon composite. Indian Patent, Application No. 1713/CHE/2012 (2012).

[6] Krenkel W, Berndt F. C/C-SiC composites for space applications and advanced friction systems. Mater Sci Eng A, 412, 177 (2005). http://dx.doi.org/10.1016/j.msea.2005.08.204.

[7] Botelho EC, Silva RA, Pardini LC, Rezende MC. A review on the development and properties of continuous fiber/epoxy/aluminum hybrid composites for aircraft structures. Mater Res, 9, 247 (2006). http://dx.doi.org/10.1590/S1516-14392006000300002.

[8] Xu Y, Zhang Y, Cheng L, Zhang L, Lou J, Zhang J. Preparation and friction behavior of carbon fiber reinforced silicon carbide matrix composites. Ceram Int, 33, 439 (2007). http://dx.doi.org/10.1016/j. ceramint.2005.10.008.

[9] Balat M, Flamant G, Male G, Pichelin G. Active to passive transition in the oxidation of silicon carbide at high temperature and low pressure in molecular and atomic oxygen. J Mater Sci, 27, 697 (1992). http://dx.doi.org/10.1007/BF02403882.

[10] Krenkel W, Heidenreich B, Renz R. C/C-SiC composites for advanced friction systems. Adv Eng Mater, 4, 427 (2002). http:// dx.doi.org/10.1002/1527-2648(20020717)4:7<427::AIDADEM427>3.0.CO;2-C

[11] Xu Y, Zhang L. Three-dimensional carbon/silicon carbide composites prepared by chemical vapor infiltration. J Am Ceram Soc, 80, 1897 (1997). http://dx.doi.org/10.1111/j.1151-2916.1997.tb03069.x.

[12] Xu Y, Cheng L, Zhang L, Yin H. Research on continuous fiber reinforced silicon carbide composites. Guisuanyan Xuebao (J Chin Ceram Soc), 30, 184 (2002).

[13] Strife JR, Brennan JJ, Prewo KM. Status of continuous fiberreinforced ceramic matrix composite processing technology. In: Wachtman JB, ed. A Collection of Papers Presented at the 14th Annual Conference on Composites and Advanced Ceramic Materials: Part 1 of 2: Ceramic Engineering and Science Proceedings, Volume 11, Issue 7/8, John Wiley \& Sons, 871 (2008). http://dx.doi. org/10.1002/9780470313008.ch26.

[14] Hongfeng Y, Yongdong X, Laifei C, Litong Z. Study on preparation and properties of continuous carbon fiber-reinforced silicon carbide composites. Guisuanyan Xuebao (J Chin Ceram Soc), 28, 437 (2000).

[15] Zhang Y, Li S, Han J, Zhou Y. Fabrication and characterization of random chopped fiber reinforced reaction bonded silicon carbide composite. Ceram Int, 38, 1261 (2012). http://dx.doi.org/10.1016/j. ceramint.2011.08.058

[16] Li S, Zhang Y, Han J, Zhou Y. Effect of carbon particle and carbon fiber on the microstructure and mechanical properties of short fiber reinforced reaction bonded silicon carbide composite. J Eur Ceram Soc, 33, 887 (2013). http://dx.doi.org/10.1016/j.jeurceramsoc. 2012.10.026.

[17] Li S, Zhang Y, Han J, Zhou Y. Effects of random chopped fiber on the flexural strength and toughness of reaction bonded silicon carbide composite. Ceram Int, 38, 4695 (2012). http://dx.doi org/10.1016/j.ceramint.2012.02.053.

[18] He X, Guo Y, Zhou Y, Jia D. Microstructures of short-carbon-fiberreinforced $\mathrm{SiC}$ composites prepared by hot-pressing. Mater Charact, 59, 1771 (2008). http://dx.doi.org/10.1016/j.matchar.2008.04.006.

[19] He X, Guo Y, Yu Z, Zhou Y, Jia D. Study on microstructures and mechanical properties of short-carbon-fiber-reinforced $\mathrm{SiC}$ composites prepared by hot-pressing. Mater Sci Eng A, 527, 334 (2009). http://dx.doi.org/10.1016/j.msea.2009.08.004.

[20] Hao S, Tang H, Zhang J. Research of dispersion uniformity of carbon fiber in short carbon fiber reinforced silicon carbide composites. 7th International Forum on Strategic Technology, Tomsk, Russia (2012). http://dx.doi.org/10.1109/ifost.2012.6357538. 